\title{
Generating high variability of B chromosomes in Eyprepocnemis plorans (grasshopper)
}

\author{
M. D. LÓPEZ-LEÓN, J. CABRERO, M. C. PARDO, E. VISERAS, J. P. M. CAMACHO* \& \\ J. L. SANTOS $†$ \\ Departamento de Genética, Facultad de Ciencias, Universidad de Granada, E-18071 Granada, Spain and \\ $\dagger$ Departamento de Genética, Facultad de Biología, Universidad Complutense de Madrid, E-28040 Madrid, Spain
}

\begin{abstract}
Twenty-eight progeny analyses (PAs) performed on specimens of $E$. plorans collected from four natural Iberian populations have been informative about the transmission of rare $\mathrm{B}$ chromosome types or the de novo origin of some of them. At least 11. rare B-types have been found in addition to the predominant ones: $B_{1}$ in Daimuz, $B_{2}$ in Jete and Salobreña, and $B_{5}$ in Fuengirola. The presence in two controlled crosses of one embryo carrying a B-type which was absent in the parents suggests that these $\mathrm{B}$ variants $\left(\mathrm{B}_{2 \text { iso }}\right.$ and $\left.\mathrm{B}_{1 \mathrm{ff}}\right)$ have originated de novo. Eleven other PAs suggest that new $\mathrm{B}$ derivatives are recurrently arising in these populations. The most frequent $\mathrm{B}$ chromosome mutation was centromere misdivision that originated four different B-types $\left(\mathrm{B}_{2 \mathrm{~m} 1}, \mathrm{~B}_{1 \text { iso }}, \mathrm{B}_{2 \text { iso }}\right.$ and $\left.\mathrm{B}_{\min i}\right)$. Other rearrangements were pericentric inversions $\left(B_{2 i 1}, B_{2 i 2}\right.$ and $\left.B_{2 i 3}\right)$, inverse tandem fusion $\left(B_{2 i t 1}\right)$, centric fusion $\left(\mathrm{B}_{1 \mathrm{f1}}\right)$ and deletions $\left(\mathrm{B}_{2 \mathrm{~d} 1}\right.$ and $\left.\mathrm{B}_{2 \mathrm{~d} 2}\right)$. The four $\mathrm{B}$ derivatives produced by centromeric misdivision are significantly eliminated during sexual transmission, most probably owing to deficiencies in the control of chromosome movement by their hemicentromeres. Those derived from translocations showed Mendelian transmission but deletion $\mathrm{B}$ variants showed a tendency to elimination. Our results suggest that $B$ chromosome substitution of $B_{1}$ by $B_{2}$ in the Salobrena and Jete populations could be achieved by differences in relative transmission efficiency, as in one controlled cross, where the female carried $1 \mathrm{~B}_{1}$ plus $1 \mathrm{~B}_{2}, \mathrm{~B}_{2}$ was significantly overtransmitted and $\mathrm{B}_{1}$ eliminated.
\end{abstract}

Keywords: B chromosomes, coevolution, drive, genomic parasitism.

\section{Introduction}

B chromosomes constitute one of the most intriguing polymorphisms present in a large number of natural populations of plant and animal species (Jones \& Rees, 1982). Some properties of Bs have been investigated, mainly from the cytological point of view, although questions about their origin and their maintenance in natural populations remain largely unsolved.

One of the most striking $\mathrm{B}$ chromosome polymorphisms described to date is that shown by the grasshopper Eyprepocnemis plorans. Bs are present in almost all natural populations from the entire geographical distribution in the Iberian Peninsula, i.e. the Mediterranean and Atlantic coastal regions from Huelva to Tarragona. About 30 different $B$ variants have been distinguished according to different morphology and C-banding patterns (Henriques-Gil \&

*Correspondence.
Arana, 1990) although three types are prevalent: $B_{1}$, $\mathrm{B}_{2}$ and $\mathrm{B}_{5} . \mathrm{B}_{1}$ is the most frequent in all the populations of the eastern (from Tarragona to Almería) and western zones (Cádiz and Huelva) of distribution, and for this reason it has been considered the original $\mathrm{B}$ in the Iberian Peninsula (Henriques-Gil et al., 1984). $\mathrm{B}_{2}$ is the main type in the province of Granada and eastern Málaga, and $\mathrm{B}_{5}$ is restricted to western Málaga.

The evolution of $\mathrm{Bs}$ implies their origin from the chromosomes of the standard complement and subsequent differentiation to their present form. Furthermore, in populations of a given species different but related $\mathrm{B}$ variants can also be generated and the establishment and maintenance of these variants will depend on their transmission and their effects on the fitness of B-carriers. Most Bs investigated to date show accumulation mechanisms that may be enough to explain their maintenance even though the Bs are detrimental to carrier fitness (Nur, 1977). The three main types of Bs of $E$. plorans constitute an exception to this 
general rule as they are transmitted in a Mendelian ratio in populations where they are the most frequent $B$ variant: $B_{1}$ at Daimuz (Valencia), $B_{2}$ at Jete and Salobreña (Granada) and $\mathrm{B}_{5}$ at Fuengirola (Málaga). The possible causes of maintenance of this widespread polymorphism have been discussed by López-León et al. (1992). The present paper deals with the transmission rates of rare $\mathrm{B}$ variants that have appeared in the populations mentioned above and demonstrates the $d e$ novo origin of some of them and their possibilities of maintenance in subsequent generations.

\section{Materials and methods}

Specimens of the grasshopper E. plorans were collected at Daimuz (Valencia), Jete and Salobreña (Granada) and Fuengirola (Málaga). A large number of progeny analyses (PAs) were performed on controlled crosses (single or double) and gravid females, from which 28 showed the transmission mode of rare B chromosome types or else the de novo origin of new $\mathrm{B}$ variants. All methods employed in the present investigation are similar to those previously described (López-León et al., 1991, 1992).

Seven progeny analyses were obtained by means of single (2) or double (5) crosses in which a female was mated to one or two males, respectively. Two double crosses were made by substitution so that they are separated into two independent PAs, one for each male, according to López-León et al. (1991). In the remaining one, both males were placed simultaneously with the female and the frequency of mating exhibited by each male recorded, for which purpose one of the males was marked on the pronotum with nail varnish. The other 20 PAs came from females collected in the field when they were gravid. The effective paternity displacement existing in E. plorans (López-León et al., 1993) means that gravid females may be considered as controlled crosses because the constitution of the parental male can be inferred from the offspring with a high degree of confidence on the basis of Mendelian transmission exhibited by $\mathrm{B}_{1}, \mathrm{~B}_{2}$ and $\mathrm{B}_{5}$ chromosomes. PAs are coded as $\mathrm{C}$ (single crosses), DC (double crosses) or $\%$ (gravid females), followed by the code number, the initial of the population $(\mathrm{D}, \mathrm{J}, \mathrm{S}$ or $\mathrm{F})$ and the year of sampling.

\section{Results}

Figure 1 shows the C-banding pattern of all types of Bs found in the progeny analyses (PAs) performed in this work. They are in addition to the standard complement of $22+\mathrm{X} \sigma^{2} / 22+\mathrm{XX}$ ? chromosomes.

The three main Bs show the following characteristics:

(1) $B_{1}$ shows two similar sized C-bands on the long arm, the light distal region being conspicuously larger than the two C-bands as a whole.

(2) $B_{2}$ in Daimuz also shows two C-bands of similar size on the long arm but in the Granada populations

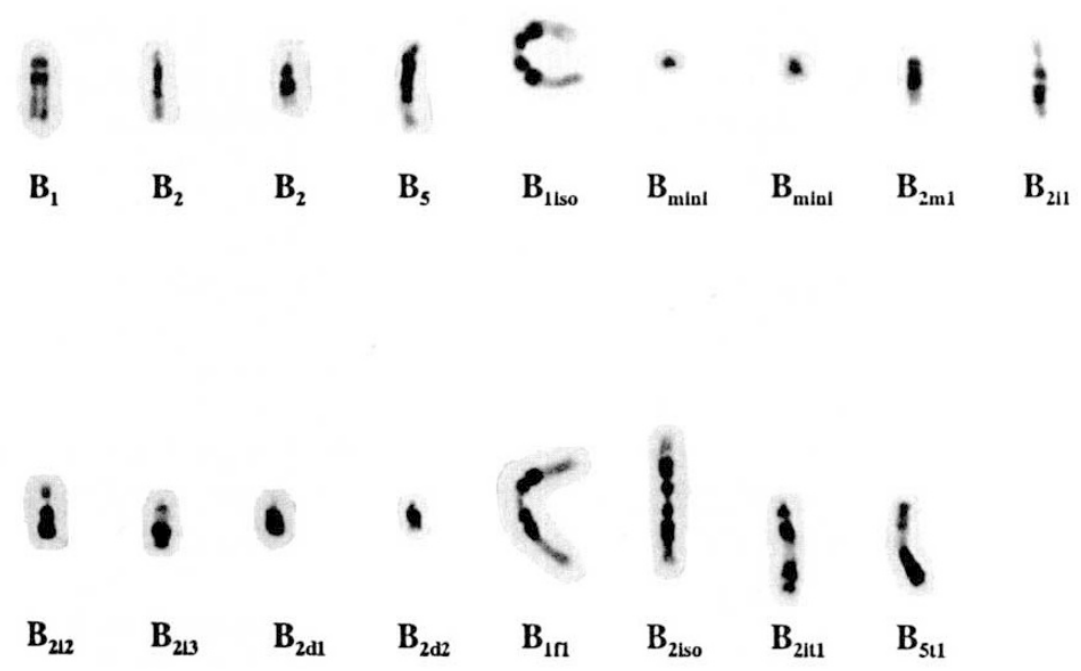

Fig. 1 Three main types of B chromosomes in E. plorans: $\mathrm{B}_{1}$ from Daimuz (Valencia), $\mathrm{B}_{2}$ from Daimuz (the first), $\mathrm{B}_{2}$ from Salobreña and Jete (Granada) (the second) and $B_{5}$ from Fuengirola (Málaga) together with 13 other $B$ variants found in these populations. $B_{\text {mini }}$ of at least two different sizes were found, which indicates that this is a heterogeneous category. 
the interstitial band is larger than the proximal one. The main difference between $B_{2}$ and $B_{1}$ is the smaller size of its light distal region.

(3) $B_{5}$ is an acrocentric chromosome similar in size to $\mathrm{B}_{1}$ but with a much larger $\mathrm{C}$-band near the centromere and smaller light distal region.

In addition to these three main types, 12 other derivatives have appeared in the four populations sampled. The number of $\mathrm{B}$ variants is very high (more than 40 , with those described in the present paper) so that it is necessary to codify their names properly in order to avoid confusion. We propose that each B variant should be named by the number of the main $B$ from which it is presumed to have been derived, followed by the initial of the chromosomal mutation from which it arose and an order number. For example, $\mathrm{B}_{2 \mathrm{i} 2}$ means that this $\mathrm{B}$ type is derived from the $\mathrm{B}_{2}$ through an inversion and that it is the second $\mathrm{B}$ variant risen from this type of rearrangement.

Besides $\mathrm{B}_{1}$ and $\mathrm{B}_{2}$, in Daimuz two other $\mathrm{B}$ variants appeared:

(1) $\mathrm{B}_{1 \text { iso }}$, which is an iso $\mathrm{B}_{1}$ derived from centromere misdivision and subsequent chromatid non-disjunction. This $\mathrm{B}$ type was originally described as $\mathrm{B}_{12}$ by Henriques-Gil et al. (1984).

(2) $B_{\text {mini }}$, which is small, about the size of the short arm plus a hemicentromere, and has also arisen through centromere misdivision. This B-type must be heterogeneous as mini Bs can be derived from many other B variants, specifically from any Bs possessing a short arm.

Nine other B-types have appeared in Granada populations besides $\mathrm{B}_{1}, \mathrm{~B}_{2}$ and $\mathrm{B}_{\text {mini }}$ :

(1) $B_{2 m 1}$ is a $B_{2}$ that has lost the short arm as a consequence of centromere misdivision. It could also have arisen from deletion of the short arm but the propensity of $\mathrm{B}_{2}$ to suffer centromere misdivision generating $\mathrm{B}_{2 \text { iso }}$ and $\mathrm{B}_{\text {mini }}$ chromosomes with low transmission rates, as we will see later, indicates that $B_{2 m 1}$ is most probably derived from misdivision as it also shows a marked tendency to elimination.

(2) $B_{2 i 1}$ shows part of the light distal zone of the long arm located on the short arm as the result of a pericentric inversion.

(3) $\mathrm{B}_{2 \mathrm{i} 2}$ shows the entire light distal region of the long arm located on the short arm.

(4) $\mathrm{B}_{2 \mathrm{i} 3}$ in which the proximal $\mathrm{C}$-band is very small and the remaining long arm has changed its order, $\mathrm{C}$ band material being distally located and the light zone being interstitially located.

(5) $\mathrm{B}_{2 \mathrm{dl}}$ is a $\mathrm{B}_{2}$ without the light distal region which has been deleted.

(6) $\mathrm{B}_{2 \mathrm{~d} 2}$ has lost the interstitial C-band and part of the light region.
(7) $B_{1 f 1}$ is the result of a centric fusion between two $B_{1}$ chromosomes.

(8) $\mathrm{B}_{2 \text { iso }}$ is an isochromosome derived from the $\mathrm{B}_{2}$ by means of centromere misdivision and subsequent chromatid non-disjunction.

(9) $\mathrm{B}_{2 \mathrm{it1} 1}$ is the result of an inverse tandem fusion between two $\mathrm{B}_{2}$ chromosomes with the loss of the centromere and the short arm in one of them.

Finally, one $\mathrm{B}$ variant appeared in Fuengirola besides $\mathrm{B}_{5}$ and $\mathrm{B}_{\text {mini }}$ : $\mathrm{B}_{5 \mathrm{t} 1}$ which shows the $\mathrm{C}$-banded region located at the end of the long arm as a result of an intrachromosomal translocation.

\section{Inheritance of rare B chromosome variants}

The results of all the progeny analyses are shown in Table 1. Details concerning them are the following.

$B_{l}, B_{2 m l}$ and $B_{2 i s o}$. Previous reports (Henriques-Gil et al., 1984; Henriques-Gil \& Arana, 1990) indicated that $\mathrm{B}_{1}$ was apparently absent from the provinces of Granada and eastern Málaga. The two populations analysed by us in this area (Jete and Salobreña) have shown the presence of this type of B although in a low number of individuals. Thus, seven of our PAs have permitted the analysis of the mode of inheritance of this chromosome in four of which it was transmitted simultaneously with another $\mathrm{B}$ variant $\left(\mathrm{B}_{2 \mathrm{~m} 1}\right.$ or $\left.\mathrm{B}_{2}\right)$ through the same parent.

In $\$ 43 \mathrm{~J} 90$, the female lacked Bs and the male presumably possessed $1 \mathrm{~B}_{1}$ which was slightly, but not significantly, undertransmitted (transmission rate, $K=0.364)$. The $\$ 31 \mathrm{~J} 90$ female carried $1 \mathrm{~B}_{2}$ and the inferred male $1 \mathrm{~B}_{1}+1 \mathrm{~B}_{2}$, both $\mathrm{Bs}$ being transmitted according to a Mendelian ratio. The $\$ 24 S 90$ was the third progeny analysis in which the male parent presumably carried a $\mathrm{B}_{1}$ accompanied, in this case, by the $B_{2 m 1}$. Both Bs were significantly eliminated.

The four remaining progeny analyses showed $B_{1}$ transmission by the female side. The female 96587 carried $1 \mathrm{~B}_{2}$ that was binomially transmitted $(K=0.559)$. Its progeny also showed the presence of one $\mathrm{B}_{2 \text { iso }}$ in 35.6 per cent of the embryos so that it may be inferred that the male parent probably carried $1 \mathrm{~B}_{2 \text { iso }}$ which was significantly undertransmitted. The three remaining progeny analyses correspond to two double crosses in which the female parent carried $1 \mathrm{~B}_{1}$ plus $1 \mathrm{~B}_{2}$. In DC10J89a, the male parent carried $1 \mathrm{~B}_{2}$, so that the mean numbers of $\mathrm{B}_{2} \mathrm{~s}(1.024)$ and $\mathrm{B}_{1} \mathrm{~s}(0.595)$ in the offspring were consistent with Mendelian expectations ( 1 and 0.5 , respectively). In DC10J89b the same female as in the preceding PA, now crossed to a $0 \mathrm{~B}$ male, again transmitted her $B_{1}$ and $B_{2}$ in rates consistent with binomial expectations $(0.523$ and 0.538 , 


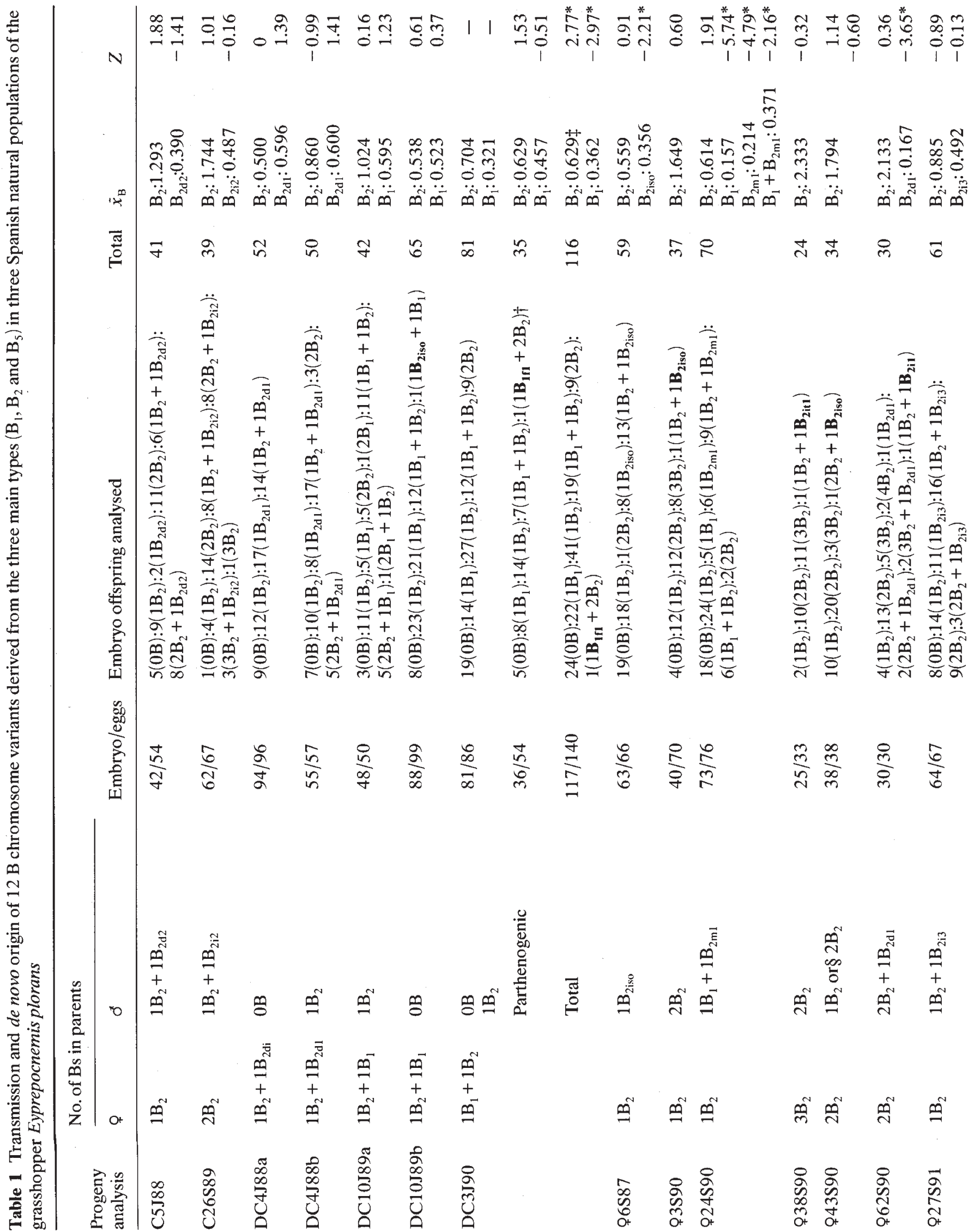




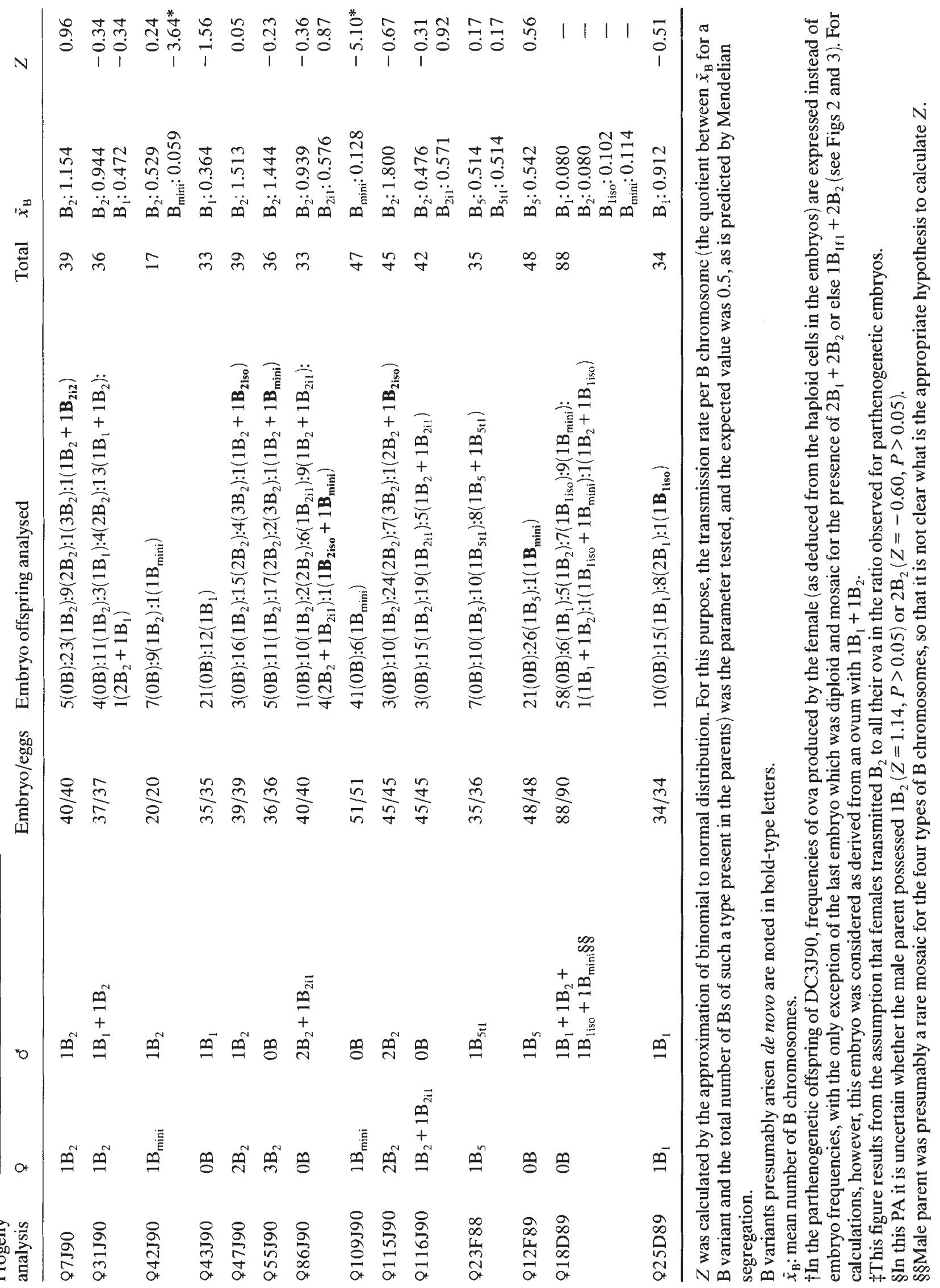


respectively). The progeny reflects exactly the composition of the ova produced by the female: $8(0 \mathrm{~B}): 21$ $\left(1 \mathrm{~B}_{1}\right): 23\left(1 \mathrm{~B}_{2}\right): 13\left(1 \mathrm{~B}_{1}+1 \mathrm{~B}_{2}\right)$ as the male lacked Bs. The last class included one embryo with $1 \mathrm{~B}_{1}+1 \mathrm{~B}_{2 \text { iso }}$, which will be considered later. These figures allow us to infer the segregation of these B-types during female meiosis. If they segregate at random, similar frequencies of the four types of embryos would be expected (16.25). A Chi-square test showed that $B_{1}$ and $B_{2}$ did not segregate randomly during female meiosis $\left(\chi^{2}=9.03\right.$, d.f. $\left.=3, P=0.01-0.05\right)$, owing to an excess of migrations to opposite poles (44 embryos with $1 \mathrm{~B}_{1}$ or $1 \mathrm{~B}_{2}$ ) to the detriment of migrations to the same pole (21 embryos with $1 \mathrm{~B}_{1}+1 \mathrm{~B}_{2}$ or without $\mathrm{Bs}$ ). This indicates that $B_{1}$ and $B_{2}$ segregate in 67.69 per cent of the first meiotic divisions, as would be expected if $B_{1}$ and $\mathrm{B}_{2}$ formed a bivalent in 35.38 per cent of cells, and this determined their migration to opposite poles.

The last progeny analysis in which $\mathrm{B}_{1}$ transmission could be analysed is DC3J90. As Table 1 shows, $B_{1}$ was carried exclusively by the female and the mean number of $\mathrm{B}_{1}$ chromosomes among the progeny (0.362) showed significant elimination through the female $(Z=-2.97, P<0.05)$. $\mathrm{B}_{2}$, however, was carried by the female and also by one of the two males placed with her. Both males copulated with the female and so paternal $\mathrm{B}_{2}$ inheritance cannot be analysed with confidence. Maternal $\mathrm{B}_{2}$ transmission, however, could be ascertained because the two latter egg-pods laid by the female contained 35 haplo-diploid embryos produced by accidental thelytoky. The number of $\mathrm{B}_{2}$ chromosomes in the haploid cells of these embryos should correspond to the number in ova $(0.629$, see Table 1$)$. If this figure were assumed to be valid for the 116 ova produced, then this transmission ratio showed significant $\mathrm{B}_{2}$ accumulation $(Z=2.77, P<0.05)$. Hence, this female showed significant tendencies to $B_{2}$ accumulation and $\mathrm{B}_{1}$ elimination.

$B_{\text {mini }}$. Two progeny analyses ( $\$ 42 \mathrm{~J} 90$ and $\$ 109 \mathrm{~J} 90$ ) comprising a gravid female and her offspring showed the transmission of the $\mathrm{B}_{\text {mini }}$ chromosome. Both females, but a significant minority of her offspring, carried the $\mathrm{B}_{\operatorname{mini}}$ chromosome (Table 1). As a whole, only 7 of 64 embryos analysed from both females carried the $B_{\text {mini }}$ so that its mean transmission ratio $(0.109)$ was significantly lower than the expected one $(Z=-6.26, P<0.05)$.

$B_{2 d l}$. Three progeny analyses showed the transmission mode of this chromosome. Two of them corresponded to the DC4J88 cross in which the female carried $1 \mathrm{~B}_{2}$ plus $1 \mathrm{~B}_{2 \mathrm{~d} 1}$, the first male lacked $\mathrm{B}$ chromosomes and the second male carried $1 B_{2}$. Transmission rates of $B_{2}$ and $\mathrm{B}_{2 \mathrm{~d} 1}$ were consistent with Mendelian expectations (Table 1). The other progeny analysis was $\$ 62 S 90$ in which the female carried $2 \mathrm{~B}_{2}$ and, on the basis of offspring karyotypes, the male was inferred to possess $2 \mathrm{~B}_{2}$ plus $1 \mathrm{~B}_{2 \mathrm{~d} 1}$. Thus, the transmission rate $(0.167)$ of $B_{2 d 1}$ was significantly lower than expected.

$B_{2 d 2}$. The only progeny analysis for this B chromosome type was performed by means of a single cross, C5J88, in which the female carried $1 \mathrm{~B}_{2}$ and the male $1 \mathrm{~B}_{2}$ plus $1 \mathrm{~B}_{2 \mathrm{~d} 2}$. This cross showed a tendency to an accumulation of $\mathrm{B}_{2}$ and elimination of $\mathrm{B}_{2 \mathrm{~d} 2}$ although the results did not reach statistical significance (Table 1 ).

$B_{2 i l}$. Two PAs, $\$ 86 \mathrm{~J} 90$ and $\$ 116 \mathrm{~J} 90$, showed Mendelian transmission of this B chromosome variant through both sexes.

$B_{2 i 2}$. One PA, C26S89, showed that the transmission mode of this $\mathrm{B}$ type by the male side was consistent with Mendelian expectations.

$B_{2 i 3}$. One PA, $\$ 27 \mathrm{~S} 91$, showed Mendelian transmission rate of this $\mathrm{B}$ variant by the male side.

$B_{5 t l}$. The female $\$ 23 \mathrm{~F} 88$ carried $1 \mathrm{~B}_{5}$ that was binomially transmitted. In the offspring one $B_{5+1}$ also appeared, so it can be inferred that the male parent carried it, and that this B variant was transmitted according to Mendelian rules.

\section{De novo origin of $B$ chromosome variants}

Thirteen PAs have demonstrated the appearance of B chromosome types that were not present in the parents, or else their presence was unlikely. Two of them were double crosses in which the new type was absent from the female and the two males crossed with her. Thus, one embryo out of 107 yielded by the DC10J89 female carried $1 \mathrm{~B}_{2 \text { iso }}$ chromosome (plus $1 \mathrm{~B}_{1}$ ) which most likely arose by centromere misdivision and chromatid non-disjunction of the maternal $B_{2}$. $A$ female embryo mosaic showing cells with either two $\mathrm{B}_{1}$ chromosomes (plus $2 \mathrm{~B}_{2}$ ) (Fig. 2) or with $1 \mathrm{~B}_{1 \mathrm{ff}}$ (plus $2 \mathrm{~B}_{2}$ ) (Fig. 3) was found among the offspring produced by parthenogenesis in DC3J90. $\mathrm{B}_{1 \mathrm{f} 1}$ had a larger centromere region than the $B_{2 \text { iso }}$ (compare both in Fig. 1), suggesting an origin by centric fusion of two $B_{1}$ chromosomes. This embryo presumably came from an ovum with $1 \mathrm{~B}_{1}$ plus $1 \mathrm{~B}_{2}$ which was subsequently diploidized, the centric fusion arising in one of the first diploid cells produced.

We can be confident in these two PAs of the de novo origin of both $\mathrm{B}$ types whereas in the remaining 11 this 


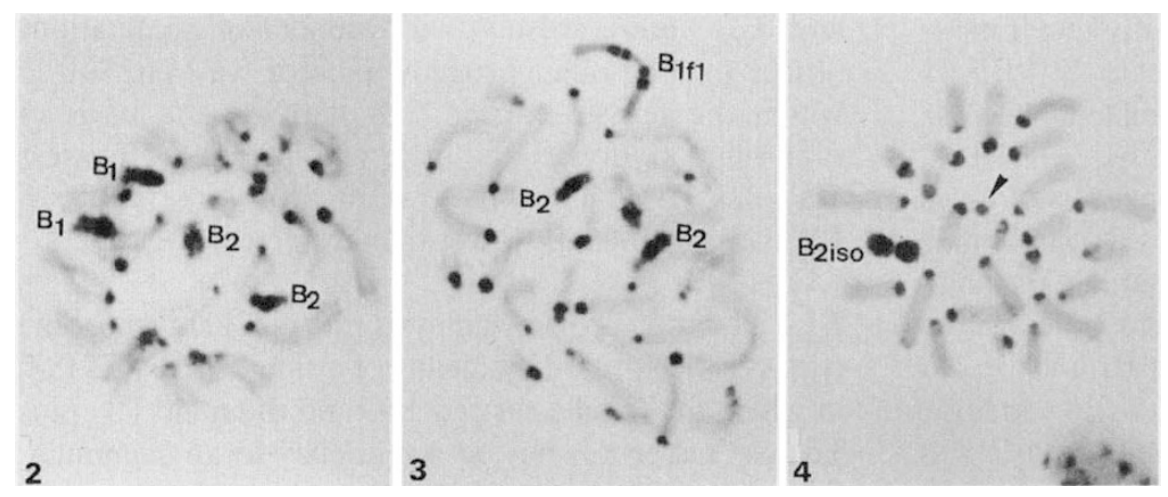

Figs 2-4 Mitotic metaphase cells of embryos of E. plorans. Fig. 2 Cell from a mosaic embryo carrying $2 \mathrm{~B}_{1}+2 \mathrm{~B}_{2}$ chromosomes. Fig. 3 Cell from the same embryo as in Fig. 2 showing $1 \mathrm{~B}_{1 \mathrm{f1}}+2 \mathrm{~B}_{2}$ chromosomes. Fig. 4 Cell from an embryo possessing $1 B_{2 \text { iso }}$ plus $1 B_{\text {mini }}$ (arrowhead).

Table 2 Frequency of different types of B chromosomes found in embryos yielded by gravid females collected at Jete ( 55 females) and Salobreña (29) populations. Mutation rates have been calculated assuming that a single embryo in a PA carrying a B type that was not present in the mother, has arisen de novo

\begin{tabular}{|c|c|c|c|c|c|c|}
\hline \multirow[b]{2}{*}{ B type } & \multirow[b]{2}{*}{ Population } & \multicolumn{4}{|c|}{ Mean number of $B$ s in } & \multirow[b]{2}{*}{ Mutation rat } \\
\hline & & Embryos & $N$ & Adults & $N$ & \\
\hline $\mathbf{B}_{1}$ & $\begin{array}{l}\text { Jete } \\
\text { Salobreña }\end{array}$ & $\begin{array}{l}0.0139 \\
0.0119\end{array}$ & $\begin{array}{r}2091 \\
921\end{array}$ & $\begin{array}{l}0.0182 \\
0.0172\end{array}$ & $\begin{array}{r}110 \\
58\end{array}$ & - \\
\hline $\mathbf{B}_{2 \text { iso }}$ & $\begin{array}{l}\text { Jete } \\
\text { Salobreña }\end{array}$ & $\begin{array}{l}0.0014 \\
0.0022\end{array}$ & $\begin{array}{r}2091 \\
921\end{array}$ & $\begin{array}{l}0 \\
0.0172\end{array}$ & $\begin{array}{r}110 \\
58\end{array}$ & $\begin{array}{l}0.0014 \\
0.0021\end{array}$ \\
\hline $\mathrm{B}_{\text {mini }}$ & $\begin{array}{l}\text { Jete } \\
\text { Salobreña }\end{array}$ & $\begin{array}{l}0.0042 \\
0\end{array}$ & $\begin{array}{r}2091 \\
921\end{array}$ & $\begin{array}{l}0.0182 \\
0\end{array}$ & $\begin{array}{r}110 \\
58\end{array}$ & $\begin{array}{l}0.0009 \\
-\end{array}$ \\
\hline$B_{2 i 1}$ & $\begin{array}{l}\text { Jete } \\
\text { Salobreña }\end{array}$ & $\begin{array}{l}0.0202 \\
0.0010\end{array}$ & $\begin{array}{r}2091 \\
921\end{array}$ & $\begin{array}{l}0.0182 \\
0\end{array}$ & $\begin{array}{r}110 \\
58\end{array}$ & $\overline{0.0010}$ \\
\hline $\mathrm{B}_{2 \mathrm{i} 2}$ & $\begin{array}{l}\text { Jete } \\
\text { Salobreña }\end{array}$ & $\begin{array}{l}0.0005 \\
0\end{array}$ & $\begin{array}{r}2091 \\
921\end{array}$ & $\begin{array}{l}0 \\
0\end{array}$ & $\begin{array}{r}110 \\
58\end{array}$ & $\begin{array}{l}0.0005 \\
-\end{array}$ \\
\hline $\mathbf{B}_{2 \mathrm{~d} 1}$ & $\begin{array}{l}\text { Jete } \\
\text { Salobreña }\end{array}$ & $\begin{array}{l}0 \\
0.0052\end{array}$ & $\begin{array}{r}2091 \\
921\end{array}$ & $\begin{array}{l}0 \\
0.0172\end{array}$ & $\begin{array}{r}110 \\
58\end{array}$ & $\begin{array}{l}- \\
-\end{array}$ \\
\hline $\mathbf{B}_{2 \mathrm{it1}}$ & $\begin{array}{l}\text { Jete } \\
\text { Salobreña }\end{array}$ & $\begin{array}{l}0 \\
0.0010\end{array}$ & $\begin{array}{r}2091 \\
921\end{array}$ & $\begin{array}{l}0 \\
0\end{array}$ & $\begin{array}{r}110 \\
58\end{array}$ & $-\overline{0.0010}$ \\
\hline $\mathbf{B}_{2 \mathrm{~m} 1}$ & $\begin{array}{l}\text { Jete } \\
\text { Salobreña }\end{array}$ & $\begin{array}{l}0 \\
0.0098\end{array}$ & $\begin{array}{r}2091 \\
921\end{array}$ & $\begin{array}{l}0 \\
0.0172\end{array}$ & $\begin{array}{r}110 \\
58\end{array}$ & - \\
\hline
\end{tabular}

possibility has to be inferred because we did not analyse the male parent. $\$ 3 S 90, \$ 43 S 90, \$ 47 J 90$ and $\$ 115 \mathrm{~J} 90$ showed the presence of a single embryo with one $\mathrm{B}_{2 \text { iso. }}$. On the other hand, one $\mathrm{B}_{1 \text { iso }}$ was found in a descendant from $\$ 25$ D89 (Table 1). Significantly, in $\$ 86 \mathrm{~J} 90$ one embryo carried two very infrequent types of $\mathrm{Bs}\left(1 \mathrm{~B}_{\text {2iso }}\right.$ plus $\left.1 \mathrm{~B}_{\text {mini }}\right)$ (Fig. 4). The probability of carrying both $\mathrm{Bs}$ from independent origins is $0.0014 \times 0.0042=5.88 \times 10^{-6}$ (see Table 2 ), so that the expected number of embryos (among the 2091 analysed in Jete) carrying both types of Bs is 0.0125 . It is likely that in this embryo $\mathrm{B}_{2 \text { iso }}$ and $\mathrm{B}_{\text {mini }}$ have a common origin by means of the same process of centromere misdivision and subsequent non-disjunction of long arm chromatids to constitute the $\mathrm{B}_{2 \text { iso }}$.

A single embryo carrying $1 \mathrm{~B}_{\text {mini }}$ was observed in the offspring from $\$ 55 \mathrm{~J} 90$ and $\$ 12 \mathrm{~F} 89 . \mathrm{B}_{2 \mathrm{i} 1}$ and $\mathrm{B}_{2 \mathrm{i} 2}$ each appeared in a single embryo from $\$ 62 \mathrm{~S} 90$ and $\$ 7 \mathrm{~J} 90$, respectively. The case of $\$ 38 \mathrm{~S} 90$ is remarkable where one embryo carried a $\mathrm{B}$ variant $\left(\mathrm{B}_{2 \mathrm{it} 1}\right)$ that has never been found in adults, so it is likely to have arisen de novo by telomere fusion of two $\mathrm{B}_{2}$ chromosomes during male or female gametogenesis. 
The progeny from $\$ 18 \mathrm{D} 89$ are of special interest as four types of $\mathrm{Bs}\left(\mathrm{B}_{1}, \mathrm{~B}_{2}, \mathrm{~B}_{\text {mini }}\right.$ and $\left.\mathrm{B}_{1 \text { iso }}\right)$ have been found (Table 1). The female parent was a non-B carrier so they must, undoubtedly, have been transmitted by the male side. The presence of $1 \mathrm{~B}_{1}$ plus $1 \mathrm{~B}_{2}$ in the same embryo indicates that both Bs must be present in the same male parent. The same deduction can be made from the observation of one embryo possessing $1 \mathrm{~B}_{1 \text { iso }}$ plus $1 \mathrm{~B}_{\text {mini }}$ and from another embryo with $1 \mathrm{~B}_{2}$ plus $1 \mathrm{~B}_{1 \text { iso. }}$. Consequently, it is likely that the four $\mathrm{B}$ types were carried by a single mosaic male parent. In this case, it was not clear what transmission hypothesis must be tested because we did not know the proportion of germ cells in this male carrying each type of $B$ chromosome.

\section{Discussion}

Some progenies shown in Table 1 constitute a clear demonstration of de novo origin of $\mathrm{B}$ chromosome variants as they were carried by a single embryo in PAs whereas the parents did not carry them. These observations suggest both that new B-types are arising (i.e. $\mathrm{B}_{2 \mathrm{it} 1}$ and $\mathrm{B}_{2 \mathrm{i} 2}$ that were present only in embryos) and that some types of $\mathrm{Bs}$ are recurrently arising in each generation (i.e. $B_{1 \text { iso }}, B_{2 \text { iso }}, B_{\text {mini }}$ and $B_{2 i 1}$ that were present in both embryos and adults). This indicates that the $\mathrm{B}$ chromosome polymorphism in E. plorans is being fed by the recurrent formation of new $B$ variants with rates ranging from $0.0005\left(\mathrm{~B}_{2 \mathrm{i} 2}\right)$ to $0.0021\left(\mathrm{~B}_{2 \text { iso }}\right)$ (Table 2). This is also supported by the appearance in a gravid female from the Salobreña population ( $\$ 27 \mathrm{~S} 91$ ) of a $B$ variant $\left(B_{2 i 3}\right)$ that was not observed in extensive samplings of this same population in precedent generations. In plants, the origin of new types of Bs from controlled crosses and experimental populations has also been reported (Bougourd \& Parker, 1979; Holmes \& Bougourd, 1991; M. Jiménez, personal communication).

Henriques-Gil et al. (1984) suggested that deletions, duplications and misdivisions are the most likely mechanisms responsible for $\mathrm{B}$ chromosome polymorphism in E. plorans. In this work, the most frequent chromosomal mutation yielding new types of Bs was centromeric misdivision that gave rise to $\mathrm{B}_{1 \text { iso }}, \mathrm{B}_{2 \text { iso }}$, $B_{\text {mini }}$ and $B_{2 m 1}$ (Fig. 5). Also relevant are putative inversions $\left(\mathrm{B}_{2 \mathrm{i} 1}, \mathrm{~B}_{2 \mathrm{i} 2}\right.$ and $\left.\mathrm{B}_{2 \mathrm{i} 3}\right)$, inverse tandem fusion $\left(\mathrm{B}_{2 \mathrm{it} 1}\right)$, centric fusion $\left(B_{1 \mathrm{f} 1}\right)$ and deletion $\left(B_{2 \mathrm{~d} 1}\right.$ and $\left.B_{2 \mathrm{~d} 2}\right)$. This indicates that the $\mathrm{Bs}$ of $E$. plorans seem to be prone to undergoing any type of chromosomal rearrangement. Translocations between $\mathrm{Bs}$ and members of the standard chromosome complement have been reported in natural populations (HenriquesGil et al., 1983; Cabrero et al., 1987). It is highly signi-

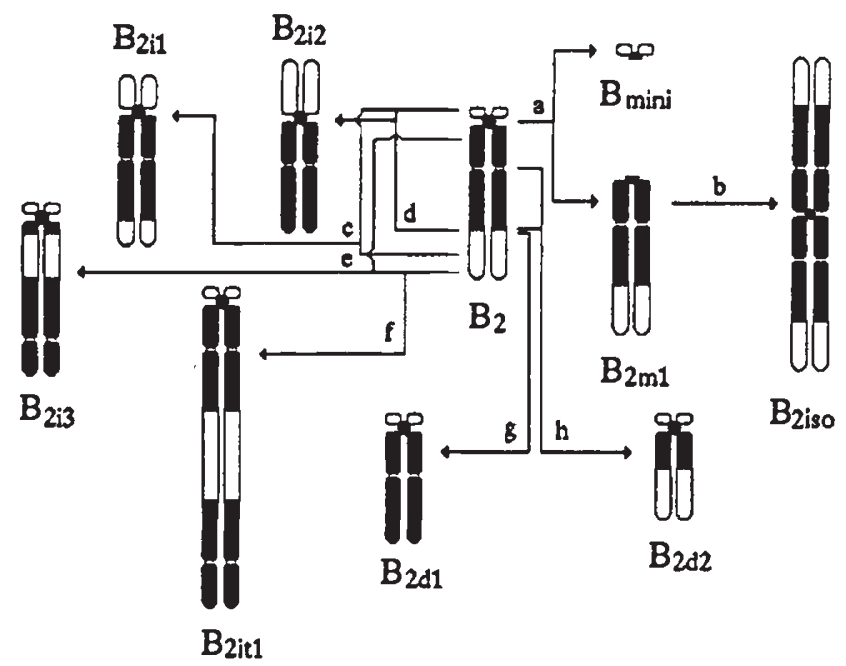

Fig. 5 Chromosomal rearrangements involved in the generation of nine $\mathrm{B}$ chromosome variants derived from $\mathrm{B}_{2}$ in natural populations of the province of Granada. In all cases the origin of the arrows point to the presumed breakage points on the $\mathrm{B}_{2}$ chromosome. a: Centromere misdivision; b: chromatid non-disjunction; $c$ and d: pericentric inversions; e: paracentric inversions; f: inverse tandem fusion; $\mathrm{g}$ and $\mathrm{h}$ : deletions.

ficant that all chromosomal mutations affecting Bs depend, as a whole, on breakage at seven main points: the short arm, the centromere, a region in the proximal C-band, the secondary constriction, the joining between the interstitial $\mathrm{C}$-band and the light distal region, and the mid and distal zones of the latter (Fig. 5).

Several chromosome rearrangements have also been proposed to explain Bs' diversity in other species. For instance: (i) B derivatives could originate as deletions and centric misdivisions in the plants Centaurea scabiosa (Fröst, 1957), Secale cereale (Lima-de-Faria, 1963), Aster ageratoides (Matsuda, 1970), Hypochoeris maculata (Parker, 1976; Parker et al., 1982), Allium schoenoprasum (Bougourd \& Parker, 1979) and Crepis capillaris (Parker et al., 1989). Remarkably, the rate of centromere misdivision giving rise to iso Bs reported in C. scabiosa $\left(1.76 \times 10^{-3}\right.$ to $\left.2.6 \times 10^{-3}\right)$ and $H$. maculata $\left(1.33 \times 10^{-3}\right.$ to $\left.1.86 \times 10^{-3}\right)$ was very similar to those we have observed in E. plorans $\left(1.4 \times 10^{-3}\right.$ to $2.1 \times 10^{-3}$ for $\mathrm{B}_{2 \text { iso }}$; Table 2). (ii) Three break insertions which are indistinguishable from inversions and addition or deletion of bands could be responsible for the differences found among some of the 23 distinct G-banding B variants observed in the grasshopper Chortoicetes terminifera (Webb \& Nehaus, 1979). (iii) $\mathrm{C}$-banding patterns displayed by Bs of the rodents Perognatus baileyi (Patton, 1977) and Uromys caudimaculatus (Baverstock et al., 1982) are consistent 
with an evolutionary model in which additions or deletions in the C-banded regions could play an important role. As Jones \& Rees (1982) have pointed out, the existence of different types of Bs within a given species is not surprising on the grounds of their relative 'inertness' because we might expect a greater tolerance to different chromosome rearrangements. It has recently been suggested (Green, 1990) that a mechanism like Muller's Ratchet could account for the evolution of some Bs as it would allow the accumulation of deletions and heterochromatinizations.

At this point, we may speculate about the scarcity of some B chromosome variants in natural populations, for instance $\mathrm{B}_{1 \text { iso }}, \mathrm{B}_{2 \text { iso }}$ and $\mathrm{B}_{\min }$, which are recurrently formed in each generation. The maintenance of newly arisen Bs depends mainly on their efficiency during sexual transmission and their effects on carrier fitness. Whereas the latter is unknown, it seems clear that Bs with a hemicentromere, as those which resulted from misdivision, show a very high tendency to elimination probably from a loss in the efficiency of the hemicentromere to control chromosome movement at meiotic anaphases during gametogenesis and even at mitotic anaphase during zygote cleavage divisions. At present, the reason for the tendency to eliminate Bs with deletions affecting the light distal region on the male side is not evident. It is conceivable that it may be related to some type of unknown function of the lost chromatin as the relocation of this region on the short $\operatorname{arm}\left(B_{2 \mathrm{i} 1}\right.$ and $\left.\mathrm{B}_{2 \mathrm{i} 2}\right)$ or on the end of the long $\operatorname{arm}\left(\mathrm{B}_{5 \mathrm{t} 1}\right)$ does not affect the characteristic Mendelian inheritance of $B_{2}$ and $B_{5}$, respectively. The increase in frequency of those $B$ variants lacking accumulation mechanisms is difficult unless they improve the fitness of individuals carrying them, a fact that is unknown at present.

The case of the $\mathrm{B}_{1}$ chromosome found in Granada province merits special mention. Most observations suggest that $B_{1}$ is the original $B$ chromosome in the Iberian Peninsula from which the remaining Bs have derived, including some types (i.e. $\mathrm{B}_{2}$ and $\mathrm{B}_{5}$ ) that are much more frequent than $B_{1}$ in certain localities (Henriques-Gil et al., 1984). This indicates that a substitution of Bs must have taken place in at least two regions, namely in Fuengirola (western Málaga) where $\mathrm{B}_{5}$ is the predominant type and the province of Granada where $B_{2}$ has substituted $B_{1}$ (see for discussion Henriques-Gil \& Arana, 1990). In Granada province, $B_{1}$ showed a trend to elimination by both sexes although it was only significant in two of the seven PAs studied. The most remarkable fact is that in the female DC $3 J 90\left(1 B_{1}+1 B_{2}\right), B_{2}$ was accumulated and $B_{1}$ eliminated, although total $\mathrm{B}$ transmission by this female was that expected for a $2 \mathrm{~B}$ carrier $(0.362+0.629=0.991)$.
The contrary situation (accumulation of $\mathrm{B}_{1}$ and elimination of $\mathrm{B}_{2}$ ) has not been observed as the female DC10J89 transmitted $B_{1}$ and $B_{2}$ at Mendelian rates. Consequently, the substitution of $B_{1}$ by $B_{2}$ in the Salobreña and Jete populations could be based on transmission efficiency differences between both variants, $B_{2}$ being favoured. If a $\mathrm{B}$ chromosome substitution is effectively taking place, and populations are near the complete substitution of $B_{1}$ by $B_{2}$, we can deduce that even hypothetical improvements of individual fitness exerted by $B_{1}$ will not be enough to counteract its elimination during transmission. The evolution of this $\mathrm{B}$ chromosome polymorphism at Málaga and Granada provinces will be the purpose of future study.

For B chromosome polymorphisms that appear to be at or near equilibrium, it is generally accepted that selective forces acting against individuals with a high number of Bs are counteracted by cytological accumulation mechanisms (Shaw \& Hewitt, 1990). In these situations mutations decreasing the transmission of the $\mathrm{B}$ will be favoured. In fact, the existence of genes in the A genome suppressing meiotic drive of $\mathrm{Bs}$ has been reported in the grasshopper Myrmeleotettix maculatus (Shaw et al., 1985), the mealy bug Pseudococcus affinis (Nur \& Brett, 1988) and rye (Romera et al., 1991). On these grounds, the B chromosome polymorphism displayed by Eyprepocnemis plorans is quite unusual because the three main variants $\left(\mathrm{B}_{1}, \mathrm{~B}_{2}\right.$ and $\left.\mathrm{B}_{5}\right)$ showed a Mendelian transmission ratio, at least in the central areas of their distribution (López-León et al., 1992). One of the most feasible hypotheses to explain the existence of the widespread B chromosome polymorphism in E. plorans is the existence of drive in the beginning (López-León et al., 1992). If drive suppressor genes were to have evolved in this species, the current situation of the polymorphism might be explained by a majority implantation in different populations of allelic variants in A chromosomes responsible for the Mendelian transmission ratio observed at present. In any case, a certain coadaptation between $\mathrm{A}$ and $\mathrm{B}$ genomes appears to have been achieved. Thus, data from the present work indicate that differences in transmission rate could play an important role in the substitution of $B_{1}$ by $B_{2}$ in Granada populations, as postulated by Henriques-Gil et al. (1984). Moreover, other different B variants are continuously arising, perhaps as a coevolutionary response to the challenges imposed by the host genome, thus being a reflection of the relationships that take place between A and B genomes. Whereas most of these new B variants will disappear from the populations in which they originate, owing to their low transmission rate (Table 3), the future of others showing 
Table 3 Transmission ratios observed for 12 B chromosome variants

\begin{tabular}{|c|c|c|c|c|c|c|c|}
\hline & \multirow[b]{2}{*}{ B type } & \multirow[b]{2}{*}{$\begin{array}{l}\text { Transmitted } \\
\text { by }\end{array}$} & \multirow[b]{2}{*}{$\begin{array}{l}\text { Progeny } \\
\text { analysis }\end{array}$} & \multirow[b]{2}{*}{$\begin{array}{l}\text { Transmission } \\
\text { ratio }\end{array}$} \\
\hline B type & $\begin{array}{l}\text { Transmitted } \\
\text { by }\end{array}$ & $\begin{array}{l}\text { Progeny } \\
\text { analysis }\end{array}$ & $\begin{array}{l}\text { Transmission } \\
\text { ratio }\end{array}$ & & & & \\
\hline \multirow{3}{*}{$\mathrm{B}_{1}$} & \multirow{3}{*}{ o } & & & \multirow{2}{*}{$\begin{array}{l}B_{2 \mathrm{~d} 2} \\
B_{2 \text { iso }}\end{array}$} & \multirow{2}{*}{ o } & C5J88 & \multirow{2}{*}{$\begin{array}{l}0.390 \\
0.356\end{array}$} \\
\hline & & $\$ 31 \mathrm{~J} 90$ & $\begin{array}{l}0.157 \\
0.472\end{array}$ & & & १6S87 & \\
\hline & & $\begin{array}{l}\text { @ } 43 \mathrm{~J} 90 \\
\text { Total }\end{array}$ & $\begin{array}{l}0.364 \\
0.331\end{array}$ & $\mathbf{B}_{5+1}$ & o & १23F 88 & 0.514 \\
\hline
\end{tabular}

Table 3 Continued
Mendelian transmission ratio is at present unpredictable.

Another situation is worthy of mention in which B chromosomes could avoid the influence of the A genome, namely their integration in this genome by means of centric fusions with regular members of the complement. This type of rearrangement has been reported to occur spontaneously in natural populations of E. plorans (Henriques-Gil et al., 1983; Cabrero et al., 1987) and has recurrently appeared in the last years either in adult individuals or in single embryos among offspring of crosses where the parents did not show such chromosomal mutation (M. D. López-León et al., unpublished data). In fact, Bs fused to an autosome do not show any cytologically detectable methylation, in contrast to free Bs, which produce the reactivation of a silent nucleolar organizer region present in the Bs (López-León et al., 1991). Therefore, both the generation of new variants and the integration in the A genome are the main evolutionary strategies displayed by $\mathrm{B}$ chromosomes in natural populations of E. plorans.

\section{Acknowledgements}

We are indebted to Mrs J. Stocco for corrections to the English. This study was partially supported by grants from the Dirección General de Investigación Científica y Técnica (no. PB90-0865) and the Plan Andaluz de Investigación, Grupo no. 3122 (Spain).

\section{References}

BAVERSTOCK, P. R., GELDER, M. AND JAHNKE, A. 1982. Cytogenetic studies of the Australian rodent Uromys caudimaculatus, a species showing extensive heterochromatin variation. Chromosoma, 84, 517-533.

BOUGOURD, S. M. AND PARKER, J. S. 1979. The B chromosome system of Allium schoenoprasum. II. Stability, inheritance and phenotypic effects. Chromosoma, 75, 369-383.

CABRERO, J., ALCHE, J. D. AND CAMACHO, J. P. M. 1987. Effects of B chromosomes of the grasshopper Eyprepocnemis plorans on nucleolar organiser regions activity. Activation of a 
latent NOR on a B chromosome fused to an autosome. Genome, 29, 116-121.

FRÖST, S. 1957. The inheritance of the accessory chromosomes in Centaurea scabiosa. Hereditas, 43, 403-422.

GREEN, D. M. 1990. Muller's Ratchet and the evolution of supernumerary chromosomes. Genome, 33, 818-824.

HENRIQUES-GIL, N. AND ARANA, P. 1990. Origin and substitution of $\mathrm{B}$ chromosomes in the grasshopper Eyprepocnemis plorans. Evolution, 44, 747-753.

HENRIQUES-GIL, N., ARANA, P. AND SANTOS, J. L. 1983. Spontaneous translocations between $B$ chromosomes and the normal complement in the grasshopper Eyprepocnemis plorans. Chromosoma, 88, 145-148.

HENRIQUES-GIL, N., SANTOS, J. L. AND ARANA, P. 1984. Evolution of a complex polymorphism in the grasshopper Eyprepocnemis plorans. Chromosoma, 89, 290-293.

HOLMES, D. S. AND BOUGOURD, S. M. 1991. B-chromosome selection in Allium schoenoprasum. II. Experimental populations. Heredity, 67, 117-122.

JONES, R. N. AND REes, H. 1982. B Chromosomes. Academic Press, London.

LIMA-DE-FARIA, A. 1963. The evolution of the structural pattern in a rye B chromosome. Evolution, 17, 289-295.

LÓPEZ-LeÓN, M. D., CABRERo, J. AND CAMACHO, J. P. M. 1991. Meiotic drive against an autosomal supernumerary segment promoted by the presence of a $\mathrm{B}$ chromosome in females of the grasshopper Eyprepocnemis plorans. Chromosoma, 100, 282-287.

LÓPEZ-LEÓN, M. D., CABRERO, J., CAMACHO, J. P. M., CANO, M. I. AND SANTOS, J. L. 1992. A widespread B chromosome polymorphism maintained without apparent drive. Evolution, 46, 529-539.

LÓPEZ-LEÓN, M. D., CABRERO, J., PARDO, M. C., VISERAS, E. AND САMACHO, J. P. M. 1993. Paternity displacement in the grasshopper Eyprepocnemis plorans. Heredity, in press.

MATSUDA, T. 1970. On the accessory chromosomes of Aster. I. The accessory chromosomes of Aster ageratoides. J. Sci. Hiroshima Univ. Ser B Div. 2 (Bot.), 13, 1-63.
NUR, U. 1977. Maintenance of a 'parasitic' B chromosome in the grasshopper Melanoplus femur-rubrum. Genetics, 87, 499-512.

NUR, U. AND BRETT, B. H. L. 1988. Genotypes affecting the condensation and transmission of heterochromatic $B$ chromosomes in the mealy bug Pseudococcus affinis. Chromosoma, 96, 205-212.

PARKER, J. s. 1976. The B chromosome system of Hypochoeris maculata. I. B-distribution, meiotic behaviour and inheritance. Chromosoma, 59, 167-177.

PARKER, J. S., JONES, G. H., EDGAR, L. AND WHITEHOUSE, C. 1989. The population cytogenetics of Crepis capillaris. II. The stability and inheritance of B chromosomes. Heredity, 63, 19-27.

PARKER, J. S., TAYLOR, S. AND AINSWORTH, C. C. 1982. The B chromosome system of Hypochoeris maculata. III. Variation in B-chromosome transmission rates. Chromosoma, 85, 229-310.

PATTON, J. L. 1977. B chromosome systems in the pocket mouse, Perognathus baileyi: meiosis and C-band studies. Chromosoma, 60, 1-14.

ROMERA, F., JIMÉNEZ, M. AND PUERTAS, M. J. 1991. Genetic control of the rate of transmission of rye $\mathrm{B}$ chromosomes. I. Effects in $2 \mathrm{~B} \times 0 \mathrm{~B}$ crosses. Heredity, 66, 61-66.

SHAW, M. W. AND HEWITT, G. M. 1990. B chromosomes, selfish DNA and theoretical models: where next? In: Futuyma, D. and Antonovics, J. (eds) Oxford Surveys in Evolutionary Biology, vol. 7, pp. 197-223.

SHAw, M. W., HEWITT, G. M. AND ANDERSON, D. A. 1985. Polymorphism in the rates of meiotic drive acting on the $B$ chromosome of Myrmeleotettix maculatus. Heredity, 55, 61-68.

WEBB, G. C. AND NEHAUS, P. 1979. Chromosome organization in the Australian plague locust Chortoicetes terminifera. II. Banding variants of $\mathrm{B}$ chromosome. Chromosoma, $\mathbf{7 0}$, 205-212. 